University of Nebraska - Lincoln

DigitalCommons@University of Nebraska - Lincoln

Architecture Program: Faculty Scholarly and

Creative Activity

Architecture Program

7-1999

\title{
Against Arbitrariness: Architectural Signification in the Age of Globalization
}

Rumiko Handa

University of Nebraska-Lincoln, rhanda1@unl.edu

Follow this and additional works at: https://digitalcommons.unl.edu/arch_facultyschol

Part of the Architecture Commons

Handa, Rumiko, "Against Arbitrariness: Architectural Signification in the Age of Globalization" (1999). Architecture Program: Faculty Scholarly and Creative Activity. 19.

https://digitalcommons.unl.edu/arch_facultyschol/19

This Article is brought to you for free and open access by the Architecture Program at DigitalCommons@University of Nebraska - Lincoln. It has been accepted for inclusion in Architecture Program: Faculty Scholarly and Creative Activity by an authorized administrator of DigitalCommons@University of Nebraska - Lincoln. 


\title{
Against Arbitrariness: Architectural Signification in the Age of Globalization
}

\author{
Rumiko Handa \\ Department of Architecture, University of Nebraska-Lincoln \\ Room 237 Architecture Hall West, Lincoln, NE 68588-0 107, USA
}

\begin{abstract}
The theory of arbitrary signification, predominant during the last half century, considers architecture's intrinsic properties as having little to do with its meaning. Consequently, architecture's significance is not based on itself but assigned externally. In the age of globalization, such an assignment is often ineffective. This paper will: (I) examine the post-WWII debates between the theories of arbitrary and natural signification; (2) relate these theories to more philosophical, historicist vs. normative positions; (3) discuss the implications concerning conservation of culture, legitimacy of interpretation, and fake authenticity in construction; (4) and examine some architectural works that have brought forth natural signification in conventional forms.
\end{abstract}

Keywords: architectural design, design philosophy, design theory, epistemology, reasoning

$\mathrm{R}$ ecently constructed churches at the growing boundary of Lincoln, Nebraska, embody the problem we face today regarding the significance of architecture (Figure 1). Here, the building has little to contribute toward its own value. Instead, any appreciation depends on the religious activities within, for which the building itself is a container. This is not just a problem of badly designed contemporary facilities. Many home-buyers are convinced that, as long as a house satisfies their functional demands, location is everything. A house becomes merely a piece of real estate with a certain resale value. Behind these lie the problems of significance and of signification in our discipline. It is a problem of significance, for the value of architecture derives not so much from architecture itself as from something that is not architecture. It is also a problem of signification, for it is rooted in the way the notion of architectural meaning itself is understood. 


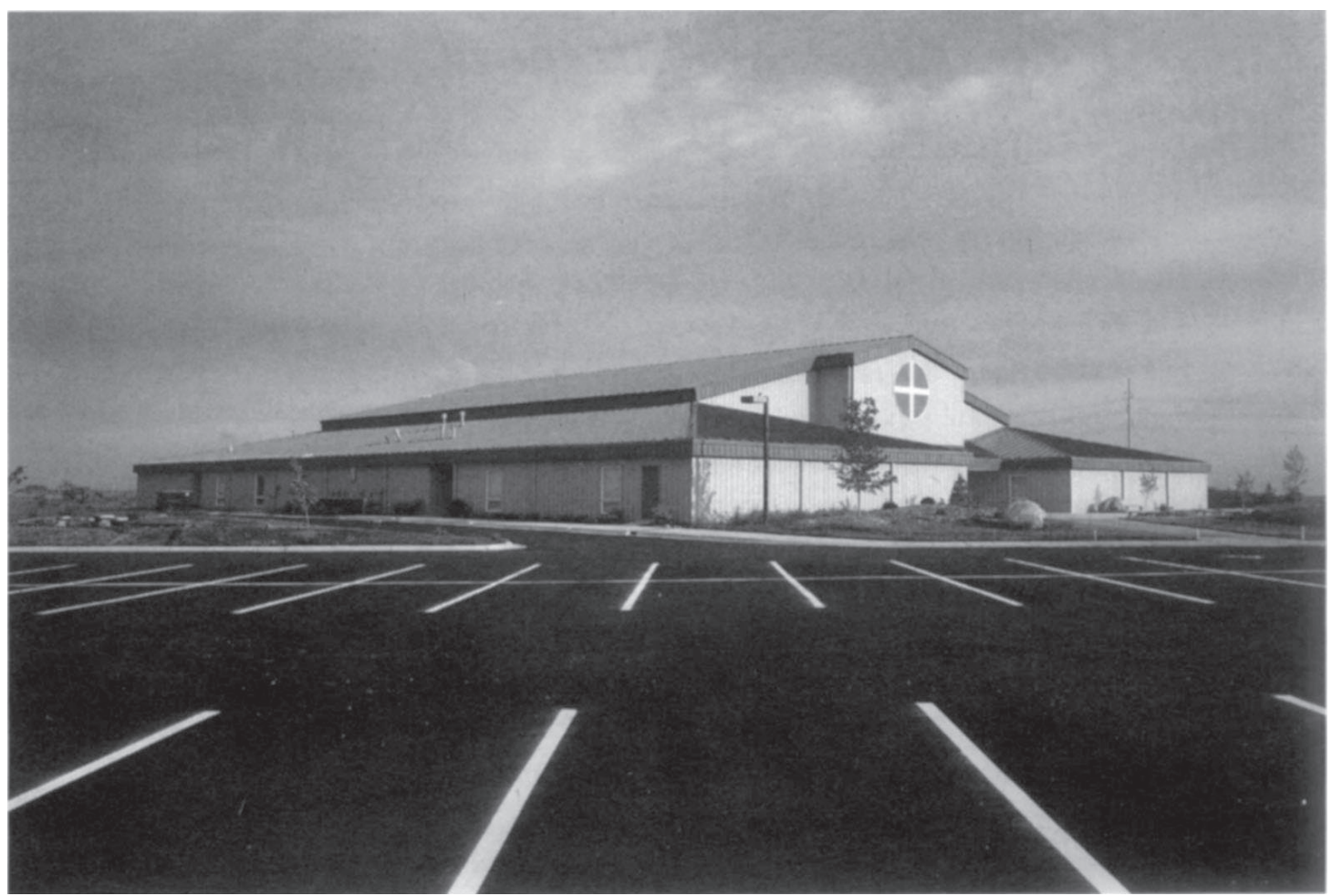

Figure 1. Faith Bible Church, Lincoln, Nebraska, USA. @ Michel Mason

There are two, generally contradictory, theories of architectural signification concerning the questions of why and how we associate a certain meaning with a piece of architecture. It is a question of episteme, or the ways in which we understand the relationship between a particular object we see before us and the meaning we may conceive lying behind it. According to one theory, in order for a piece of architecture to mean something, that meaning has to have been assigned. To many of those who hold this theory, what assigns a meaning to a piece is cultural convention. To others, including some architects and architectural students, an individual is the one who assigns a meaning. When one believes in the assigned nature of signification, whether by a culture or an individual, one tends to think that the only legitimate way to derive a meaning out of a piece is to go to the source that has assigned the signification. According to this view, the piece's physical attributes have little to do with a meaning, that is, the relationship between the piece and its meaning is arbitrary.

The theory of natural signification, on the other hand, gathers meaning from the piece's physical attributes, and therefore presumes architecture to be inherently motivated. According to 
this theory, a piece of architecture should display enough properties, be they the color, textures, sizes, or proportions, to evoke a certain meaning in a viewer's mind. This theory implies that the meaning of an architectural piece is not dependent on the viewer's a priori knowledge of a certain culture or architect. Predominant in the eighteenth century and again at the beginning of this century, this theory was eclipsed when arbitrary signification became popular in the middle of this century.

The problem at hand, that architecture escapes being understood for its own qualities, is an ontological one: it concerns both the piece of architecture having little in itself to contribute toward its understanding and the viewer caring little about the piece's intrinsic properties. This paper will, however, examine the problem from a specific point of view: architects, subscribing to the theory of arbitrary signification, have alienated the intrinsic properties of architecture from its significance, and have produced architecture accordingly. As a result, the general public shows little enthusiasm in engaging themselves with physical properties of any building.

The theory of arbitrary signification is less advantageous particularly in the age of globalization. Firstly, it puts people from other cultures at odds with meaning. To compare, a meaning based on natural signification is in principle globally accessible. If one assumes that architecture is valued when a viewer finds a meaning to it, then the theory of arbitrary signification shuns the value of architecture. The second disadvantage of the theory of arbitrary signification concerns the notion of culture. Contrary to the common understanding, the assumption of arbitrariness does not necessarily support preservation of cultures, and can instead alienate cultures. Although usually considered arbitrary, most conventional form-meaning relationships have a non-arbitrary origin, and therefore it is not only possible but also beneficial for architects to add natural signification to their designs even when they are dealing with culturally specific forms. In fact, as some examples will demonstrate, reinterpretation of conventional forms can bring forth the natural signification from physical properties.

In order to arrive at the above conclusions, this paper will first examine the intellectual debates since the Second World War, in order to see how we have come to support arbitrary signification and all too often ignored or denied natural signification. This paper will then locate the debate of the arbitrary vs. natural signification in a larger context of philosophical positions. In particular, it will be shown that the debate in hand reflects the debate on the more fundamental philosophical issues, namely that between historicist and normative positions, which has taken place since the mid-nineteenth century. Thirdly, the paper will discuss the implications of the theories of architectural signification in or- 
der to understand more fully what it might eventually mean to hold either position. The issues will include conservation of cultural identity, legitimacy of interpretation, and fake authenticity in architectural production. In the end, architects will be advised to add natural signification to their designs. Some examples will demonstrate this recommendation, in which the reinterpretation of conventional forms has reinforced natural signification of physical properties.

\section{History of Arbitrary Signification}

\subsection{Semiology in Architecture}

A regard for architecture as a system of signification is but one of many aspects of this century's general interest in signs. According to Geoffrey Broadbent, the first publication on architectural signification is Roberto Pane's Architettura e arti figurative of 1948. In the English-speaking community, the entry was slightly delayed until the late 1960s. ${ }^{1}$

The critics who considered architecture as a system of signification had a strong bias as to how a viewer derives a meaning from a piece of architecture. Swiss linguist Ferdinand de Saussure had a strong influence in this regard, who claimed that "The bond between the signifier and the signified is arbitrary." 2 The architectural critics argued that, even if a form may originally be non-arbitrary in relation to its meaning, as soon as the form-meaning relationship becomes conventionalized, the form itself ceases to be the source of that meaning. In support of this view, both Charles Jencks and Umberto Eco referred to a housing project in Southern Italy, in which the residents washed olives in toilet bowls. ${ }^{3}$ These critics argued that a form, even one that derived directly from its function, must be accompanied by a social convention or instructions for use, in order to carry that function as a meaning. Therefore, architectural meaning is said to be arbitrary, that is, a viewer cannot derive it directly from a form.

The theory of arbitrary signification was also used to criticize modernist ideology. Juan Pablo Bonta, in his 1979 book argued that the modernists did not understand that natural signs turn conventional as soon as they are accepted by society. ${ }^{4}$ Alan Colquhoun characterized modernists" "expressionist theory" that "shapes have physiognomic or expressive content which communicates itself to us directly." ${ }^{5}$ Instead, Colquhoun argued that forms were "very low in content, unless we attribute to these forms some system of conventional meanings not inherent in the forms themselves." For Colquhoun, then, culture was a necessary agent to elevate architecture above its "low content" to the level of meaning. 


\subsection{Postmodernism, Deconstruction, and Arbitrary Signification}

The theory of arbitrary signification. locating a meaning in something other than architecture itself. also grips neo-conservative postmodernists. They go even further to clearly separate the signification of architecture from architecture itself. In particular. with Robert Venturi's concept of the decorated shed. the decoration takes care of signification. while the shed. designed to fulfill the requirements of the program. is not expected to contribute to the meaning. ${ }^{6}$ Isolating the signifying form from the quintessence of the building can also be seen in Michael Graves's designs. where the figurative appearance has little to do with the way the building is made. ${ }^{7}$ With Stanley Tigerman, while no one fails to find in the floor plan a pictorial resemblance of a certain object, that object has no relevance to the way the building is being used. ${ }^{8}$

Deconstruction is not an exception, but rather an extreme when it comes to dissociating the meaning from the intrinsic properties of architecture. Peter Eisenman argues, in architecture "we do not have either an agreed-upon sign system or an elaborated grammar." From this, Eisenman proceeds to conclude that there is no meaning in architecture:

In architecture, when you build a wall, not only is it really opaque, but its relationship to a signified is very difficult to articulate. A wall is a wall, it is not a word, it is, it is never about. It is the thing that the word "wall" refers to, it is the opposite condition of a word: words are transparent whereas walls are opaque. ${ }^{9}$

Behind this logic is the assumption that any meaning needs an external system of assignment, or the theory of arbitrary signification. For Eisenman, architecture alone cannot be a source of meaning.

The theory of arbitrary signification can lead to devaluating the interpretation of architecture all together. Under the assumption of arbitrariness the agent of the assigned meaning, be it a culture or an individual architect. is the authority with absolute power over signification. Nothing else can legitimize any meaning. This authority, however, can be extremely vulnerable. For, with architecture's intrinsic properties indifferent toward signification, any viewer could claim authority for his/her own interpretation, especially when the original signification is not known. This eventually results in the relativism of interpretation. In other words, interpreting architecture becomes a futile activity. Architecture designed with this conviction is non-significative. That is, any effort of making sense out of the piece will yield nothing significant.
6.Venturi, R., Brown, D. S., and Izenour, S., Learning from Las Vegas (Cambridge: The MIT Press, 1972).

7. Graves, M., Buildings and Projects 1966-198I (New York: Rizzoli, 1982).

8. Tigerman, S., Buildings and Projects 1966-1989 (New York: Rizzoli, 1989).

9. Eisenman, P., "Architecture and the Problem of the Rhetorical Figure," Architecture and Urbanism, Vol. 202 (1987), pp. I7-20. 


\section{Historicism in Support of Arbitrary Signification}

\subsection{Historicist vs. Normative Positions}

In order to deepen our understanding of the theory of arbitrary signification, it is important to locate this theory in a larger context of epistemology, namely in the dichotomy between historicist and normative positions. ${ }^{5}$ According to the normative position, typical of the eighteenth century, a particular grammar of a language is a mere stray from a general grammar, the immutable and general principles of language. History, similarly, is to discover the constant and universal principles of human nature, while historical transformation is a mere accident of the historical process. Continuing along the same line, architecture's ethical and aesthetic value judgments, which can be obtained through the observation of the phenomenal world and the counsel of one's own natural reason, are then applicable and valid for any time period or location.

In contrast, historicism began in the late eighteenth century, and considers differences in time and space as the direct outcomes of the particular historical forces. Historicism in architecture concurs with this viewpoint in so far as a historical style is considered a reflection of a particular period. While we tend to understand Zeitgeist in the Modern Movement as raised in objection to nineteenth-century eclecticism, Colquhoun points out that eclecticism and the concept of the Zeitgeist grow from the same root of historicism. The difference in the epistemology supported by the theory of arbitrary signification and that of natural signification reflects these different philosophical positions. According to the theory of arbitrary signification, to know a meaning of an architectural piece is to have the knowledge of the agent that has assigned a meaning to that piece. To compare, the theory of natural signification assumes that a meaning can be arrived at through the observation of the piece itself. In this difference lies the dichotomy between the historicist and normative positions.

Furthermore, we might say that the mind that supports the theory of arbitrary signification is typical to modernity, as long as we see, as Colquhoun did, the characteristics of modernity in historicism. Although we tend to disengage postmodernism and deconstruction of architecture from the early modernist ideology, we might here find a particular modernity in these postwar schools of architectural thought.

\subsection{Significance of Typology}

The dichotomy between the theories of arbitrary and natural signification can be a tricky issue to those who are used to understanding a theoretical position by oppositions. Unfortunately, the 
typical modern mind tends to be quick in categorizing various positions into polar opposites. As a result, if two positions agree on something, they tend to be seen as agreeing with each other in totality.

An illuminating comparison can be made between the two positions concerning typology, namely of Colquhoun and of Carroll Westfall. ${ }^{10}$ Both architectural historians strongly support the significance of types, and yet their theoretical positions are totally different: one holds the historicist position, while the other the normative position. In particular, while Colquhoun considers that type is important because of the deposit of meanings through time, Westfall thinks that type is fundamentally based on the form's natural signification.

\section{Implications of Arbitrary Signification}

Just as any position, the theory of arbitrary signification needs to be evaluated for its implications. Three controversial issues are the question of ownership, the question of legitimate interpretation, and the question of making. We will see that the theory of natural signification cannot go through these issues unscathed, or without adjustment.

\subsection{Question of Ownership: Cultural Identity vs. Alienation}

Who, if anyone, owns architectural signification? In the case of arbitrary signification, those who have assigned and who share the particular signification have the ownership. This question has implications for the issues of cultural identity and alienation.

Many people endorse conventional signification just as they support cultural identity and conservation. Generally speaking, sharing something with a limited number of people creates a sense of belonging to a particular community. This is the case with the convention of architectural signification. It is, however, a danger if we concluded from the above that the theory of arbitrary signification is in support of cultural identity and conservation. On the contrary, arbitrary signification can cause cultural alienation and be detrimental to the conservation of culture, particularly under globalization.

First of all, arbitrary signification can alienate architectural pieces from possible viewers who may be willing to appreciate the artifacts but who do not share the signification. Many who are foreign to the culture are in this category. To make sense out of the piece they need to learn that convention. In order to learn, according to the theory of arbitrary signification, they have
10. Westfall, C. and van Pelt, R. J., Architectural Principles in the Age of Historicism (New Haven:Yale University Press, 1991). 
to take the words of those who own the convention. In no other way can they evaluate any interpretation. The least legitimate is to observe the piece itself, the natural way to appreciate an artifact. For, according to the theory of arbitrary signification, the piece itself has nothing to do with rightful signification.

The danger of alienation exists not only in a viewer foreign to the assigned signification, but also in a piece itself. An architectural piece that depends for its value on something other than its inherent properties is at the mercy of exterior conditions such as a change in usage or a shift in real estate market. In this case, architecture is alienated from its own value source. In comparison, natural signification is beneficial. Contrary to common belief, conventional signification is not necessarily arbitrary. In fact, in many cases, conventional signification is at least partly supported by natural signification. Take the example of a pyramid. As Karsten Harries has rightly put, although we consider the signification of a pyramid to be conventional, in that "Any pyramid we erect harks back to its Egyptian precursors and to the function of these structures," the signification is usually not completely arbitrary:

there is something about the simple geometry of the form that makes it not an accident that Egyptians seized on it as they did: the conventional symbol presupposes and builds on a natural symbol. ${ }^{11}$

One can design an architectural piece in such a way that it will have physical properties in itself that support the signification by convention. A viewer then has a chance of experiencing the piece for its own sake, as well as for its conventional signification. This will make the piece of architecture available and accessible instead of alienating.

Consider a design for a memorial. A memorial is usually strongly associated with a certain group of people and it has to take the best possible care of the emotional and spiritual needs of those particular individuals. Simultaneously, however, a memorial also needs to make others aware and understand the significance of what it commemorates. In fact, the worst service a memorial could do is to alienate those who are not directly involved. Here, the more arbitrary the conventional form-meaning relationship may be, the more that signification needs to be supported by the artifact's intrinsic properties.

\subsection{Question of Legitimate Interpretation: Multiple Meaning}

I I. Harries, K., "Thoughts on a Nonarbitrary Architecture," Perspecta, Vol. 20 (1983), pp. 9-20.
Closely related to the question of ownership is the question of legitimacy. On the one hand, according to the theory of arbitrary 
signification, which restricts the ownership to those who have assigned the meaning and to those who share that assignment, the only legitimate interpretation is the one identical to the original meaning. On the other hand, the theory of natural signification allows any significative properties of an architectural piece to be the basis of a meaning. If legitimacy implies definitive meaning, then the natural signification might not be a good idea. Does the theory of natural signification end up with the relativism of interpretation, just as Deconstruction did?

Here it is important to recognize difficulties of locating legitimacy in the original meaning. First of all, it is not always possible to determine the original meaning. And more importantly, the original meaning does not necessarily help architecture to stay significant in the age of globalization.

In order to illustrate these questions, Edmund Burke's passage on Stonehenge bears relevance:

\begin{abstract}
The great stones, it has been supposed, were originally monuments of illustrious men, or the memorials of considerable action: or they were landmarks for deciding the bounds of fixed property. In time, the memory of the persons or facts which these stones were erected to perpetuate wore away; but the reverence which custom, and probably certain periodical ceremonies, had preserved for those places was not so soon obliterated. The monuments themselves then came to be venerated; and not the less because the reason for venerating them was no longer known. ${ }^{12}$
\end{abstract}

According to Robert Jan van Pelt, "Burke argued that this megalithic monument had become the most sacred of the English monuments because its original intention had been forgotten."10 To get to the correct, originally intended meaning is not always possible. In addition, knowing the original meaning is not necessarily a requisite for a piece to be significant. Furthermore, knowing the original meaning does not necessarily mean that the piece is thereby significant.

The above questions concerning legitimate interpretation or the kind of signification that supports the piece's significance can be observed in the development of hermeneutics during the last two centuries. In the discipline of hermeneutics, the definition of meaning (or of understanding) shifted from the original meaning to the ontological meaning, from the eighteenth-century Romantic hermeneutics of Friedrich Schleiermacher to the twentiethcentury Phenomenological hermeneutics of Martin Heidegger and Hans-Georg Gadamer.

For Friedrich Schleiermacher, the meaning was fixed by the author's intention. Understanding the author's meaning was the goal of interpretation. Schleiermacher, however, was not uncognisant of the factors that made it difficult to reach the author's
12. Burke, E., The Works of the Right Honorable Edmund Burke, Vol. 7 (Boston: Little, Brown, and Company, 187I). 
meaning. First, the author was not fully conscious of the meaning. Second, the text may be inadequate for the meaning. Therefore, Schleiermacher thought that the interpreter's role was to understand the author better than the author.

He is distinctly Romantic in assuming that cultural interchange involves a simple identity between author and reader and that meaning is fixed by the author's intention. He assumes, moreover, a certain inadequacy in written texts, overcome through understanding as translinguistic contact between individuals.... At the psychological level, for instance, "subjective-historical" reading reconstructs the author's intention; but "subjective-divinatory" reading projects a meaning not yet expressed in the text, thus allowing Schleiermacher to make his often-cited statement that the reader understands the text better than the author does. ${ }^{13}$

The above way of understanding the legitimacy of meaning can be seen not only in Schleiermacher but also in Immanuel Kant in the following statement about Plato:

I need only to remark that it is by no means unusual ... to find that we understand him better than he has understood himself. As he has not sufficiently determined his concept, he has sometimes spoken, or even thought, in opposition to his own intention..$^{14}$

In addition, in art history, Erwin Panofsky's iconology belonged to this discussion. Panofsky categorized meaning into three levels, and the ultimate goal of iconology was to get to the original meaning, which was not usually recognized consciously by the artist.

In the twentieth century, the recognition of the historicity of both the author and the reader has brought the hermeneutic discussions to another, ontological level. With Martin Heidegger and Hans-Georg Gadamer, the historicity of those who have made an object and who interpret it has become a given. In other words, it is now assumed that the two have backgrounds not necessarily identical to each other. Meaning of an object, which lies before the interpreter, then, is not something to be found in the author, but to be reconstructed by the interpreter in such a way that there is a recognition of a "horizon," shared between the author and the interpreter in regard to this object. Understanding is not necessarily meant to reach the exactitude of the author's meaning, neither is

13. Groden, M. and Kreiswirth, M. (eds.), The Johns Hopkins Guide to Literary Theory and Criticism (Baltimore: The Johns Hopkins University Press, 1994).

14. Kant, I. Critique of Pure Reason (London: Macmillan, 1958). it to impose the interpreter's peculiar condition onto the object being interpreted. It is supposed to appreciate the fact that the object is the way it is (how it has been conceived, made, and conserved), and was made possible by other fellow human beings.

By taking understanding to be not of the original meaning, but to lie in the fact that the piece relates itself to the reader's life- 
world, the difference between the reader and the author of the background, historicity in another word, is no longer a hindrance to interpretation.

Unlike in previous hermeneutic theory, the historicality of the interpreter is not a barrier to comprehension. A truly hermeneutic thinking must take into account its own historicality (die eigene Geschichtlichkeit mitdenken). It is only a "proper hermeneutics" when it demonstrates the effectivity (Wirkung) of history within understanding itself. $^{13}$

Gadamer's hermeneutics is therefore not a simple return to the normative point of view, to which historicism was reactionary. Instead, he tries to incorporate historicity as a fact into the concept of understanding.

The above ontological interpretation, including Burke's about Stonehenge, should be clearly differentiated from any meaning by the reader. Umberto Eco, for one, has warned of the "overinterpretation" by the free play of the intentio lectoris, the intention by the reader, and instead proposed the intentio operis, based "upon the text as a coherent whole."15 In other words, including historicity of the author and the reader does not mean that anything that the reader comes up with is legitimate as an interpretation. In this regard, Gadamer explains Heidegger in the importance of examining the object in itself, in order for the interpreter to avoid imposing one's own illegitimate and inappropriate prejudice:

All correct interpretation must be on guard against arbitrary fancies and the limitations imposed by imperceptible habits of thought, and it must direct its gaze "on the things themselves" (which, in the case of the literary critic, are meaningful texts, which themselves are again concerned with objects). For the interpreter to let himself be guided by the things themselves is obviously not a matter of a single, "conscientious" decision, but is "the first, last, and constant task." For it is necessary to keep one's gaze fixed on the thing throughout all the constant distractions that originate in the interpreter himself. A person who is trying to understand a text is always projecting. He projects a meaning for the text as a whole as soon as some initial meaning emerges in the text. Again, the initial meaning emerges only because he is reading the text with particular expectations in regard to a certain meaning. Working out this fore-projection, which is constantly revised in terms of what emerges as he penetrates into the meaning, is understanding what is there. ${ }^{16}$

The possible interpretation that Burke had in front of Stonehenge should be clearly differentiated from any meaning by the reader.

A further discussion can be found in the work of Paul Ricoeur. One of those who at an early stage acknowledged a paradox between universal civilization and national cultures, Ricoeur ad-
15. Eco, U., Interpretation and Overinterpretation (Cambridge: Cambridge University Press, 1992).

16. Gadamer, H.-G., Truth and Method (New York: Crossroad, 1990). 
vanced the two-fold approach in his phenomenological hermeneutics: appropriation and distanciation. ${ }^{17}$ In the first, the goal in interpreting a text lies not so much in arriving at the subjective intention of the author, but rather in the appropriation of the text. ${ }^{18}$ Here, to appropriate a text through interpretation should be considered, as in the word's Latin etymological root appropriare, to make one's own. Appropriation of text is in fact what Ricoeur regards as the significance of his hermeneutics:

the very work of interpretation reveals a profound intention, that of overcoming distance and cultural differences and of matching the reader to a text which has become foreign, thereby incorporating its meaning into the present comprehension a man is able to have of himself. ${ }^{19}$

The goal of interpreting a piece of architecture under such conditions is then to make it one's own even without the assignment of a meaning.

Ricoeur's second issue, distanciation, is that an interpretation can be explained in its non-arbitrary relation to the text in and of itself. An interpretation can then be submitted for rational argument away from the subjective realm of the author or the interpreter. One can then study the physical attributes and properties of a piece, in its parts, whole, and relation to others, in arriving at a meaningful, that is, appropriated interpretation, or in evaluating any given interpretation.

The author, or the architect, plays a crucial role, not for the meaning he/she might assign to a form, but precisely in purposefully designing the physical properties of architecture in a nonarbitrary manner so that it may later be interpreted in a non-arbitrary way. The physical properties, which had embodied the author's meaning to the author, persist even after being detached from the author and his/her meaning. Only with these properties can a later appropriation and distanciation be possible. The piece's attributes allow the interpreter to derive his/her own appropriated interpretation, in addition to anchoring the interpretation.

\subsection{Question of Making: Fake Authenticity}

Fake authenticity is a problem both theories of signification face in today's context. ${ }^{20}$ When an object was authentic, say, in a homogeneous society of the past, the object had an integrity in itself, between the materials, the structure, the way of making, and the shape. To compare, today, when the development of technology has provided with the means of communication, transportation, and of construction, the integrity of an object is a difficult goal to achieve. When we try to create a conventional form, there tends to be a discrepancy in the product, for we have already 
changed the materials and means of construction, thereby creating fakeness. The piece may visually resemble the original, but is quite different from the original in how it is made.

This problem is especially apparent in the modern steel stud construction in which the steel studs take care of the structure but are expected to be hidden by the surface finish material. The cladding materials, stone for example, sliced so thin to be held by the studs, are deprived of their own intrinsic-structural, thermal, acoustic - properties. In addition. the steel stud construction allows acrobatic shapes with welding techniques, easily defeating the integrity of this system of vertical walls.

\section{Fusing Natural Signification into Convention}

Tadao Ando's work reveals an architect's efforts to keep the intrinsic properties of architecture intact with significance and signification. His work encourages a viewer to make an interpretation that is anchored in the piece's physical properties more than anything, and that allows the piece to be significant, in the fullest sense of this word, to the interpreter with or without reference to a convention. Commenting on Ando's buildings, Jackie Kestenbaum demonstrates this point:

To visit an Ando building is to relinquish all presuppositions about architecture and take on Ando's Weltanschauung ... to negotiate an Ando building is an arduous task, alternative exertion with contemplation, a process whereby the spatial phenomenon imprints itself upon the mind and body and resonate for days. ... It is the resonance one feels in holy places, where personal memory is not a prerequisite, where the place itself bears the weight. ${ }^{21}$

In the Church of Light (Figure 2), as in many other buildings by Ando, one encounters a carefully selected, limited number of building materials treated to their physical extreme. The intention is to present the materials in their utmost essence. Ando tries "to choose materials as a poet chooses words and to give them the most appropriate forms of expression." ${ }^{22}$ For example, Ando insists on concrete mixture so hard that it is almost impossible to distribute the material between panels. As a result, his concrete walls are dense and solid to the extreme limit. By pushing the material's physical properties almost to the impossible, the architect intends to create a structure that by itself evokes the non-physical.

For the same reason, Ando is not at all sympathetic to the use of new industrial materials in a traditional form. A pseudo-authentic application is for him not a pursuit of the material's intrinsic potential:
2I. Levene, R. C. and Cecilia, F. M., Tadeo Ando 1983-1992 (Madrid: El Croquis, 1994)

22. Ando, T., "Fifteen Years of Architectural Activity," Shinkenchiku (Nov. 1984), pp. 202-205. 
Figure 2. Tadao Ando, Church of Light, Osaka, Japan. @ Shinkenchiku-sha

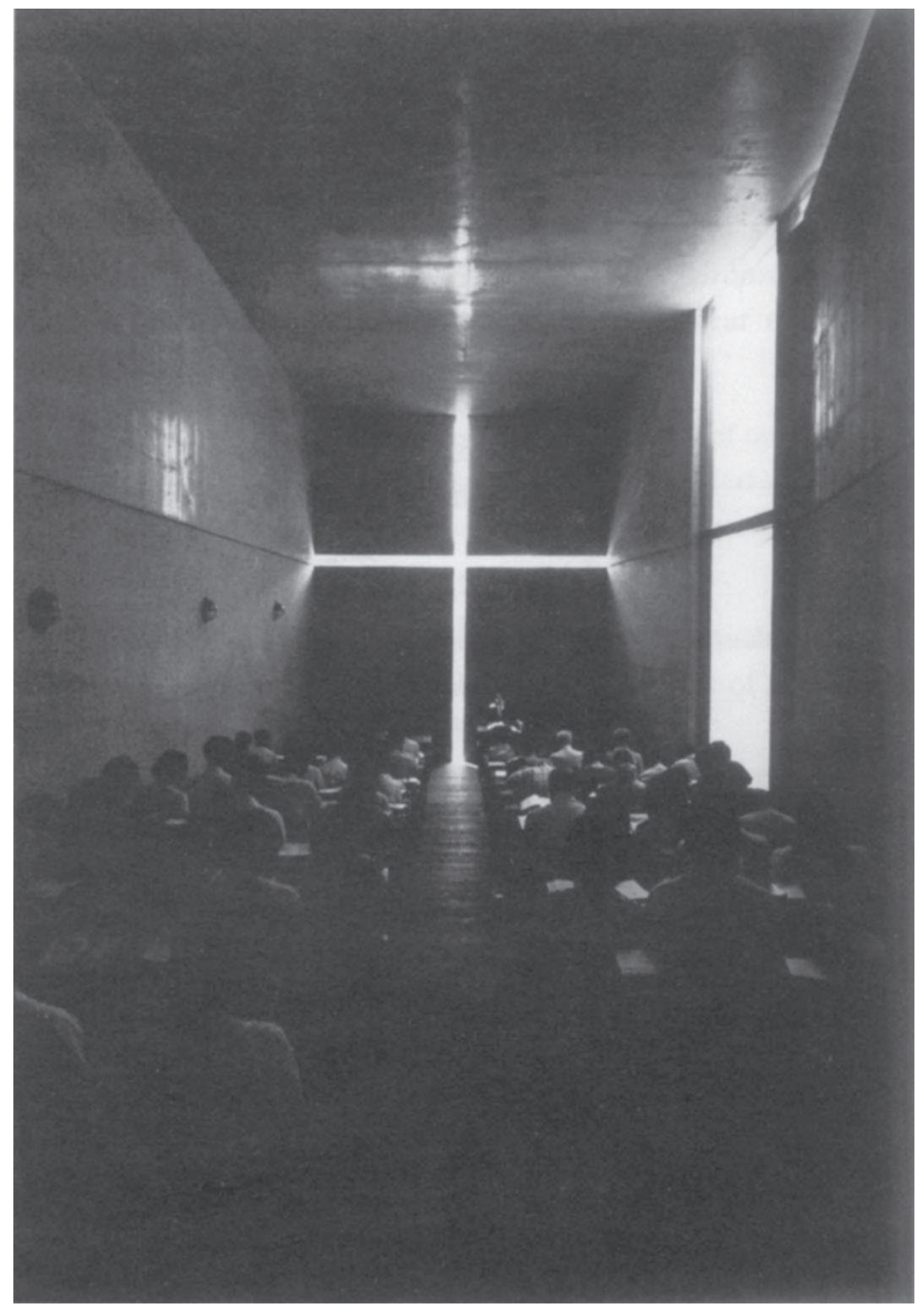

By trying to reproduce in modern materials (concrete and steel) and their suitable techniques, forms that came into being in relation to Japan's traditional building material (wood) amounted to ignoring the inevitable and fundamental connections between material and form. For this reason buildings making this attempt sustained many difficulties and before long, ceased to emerge. ${ }^{23}$

In Ando's church, even a cross is no longer a mere Christian symbol whose meaning relies on the conventional endowment. Instead, the architect has turned it into the vertical and the horizontal linear openings in the otherwise solid concrete wall, full of intrinsic properties that pronounce signification. By carefully creating the void at the end of the room, the architect succeeds in embodying the sense, so appropriate for the religious practice, of time and space beyond reach. The intrinsic properties of architecture encour-
23. Ando, T., Buildings Projects Writings (New York: Rizzoli, 1984). 


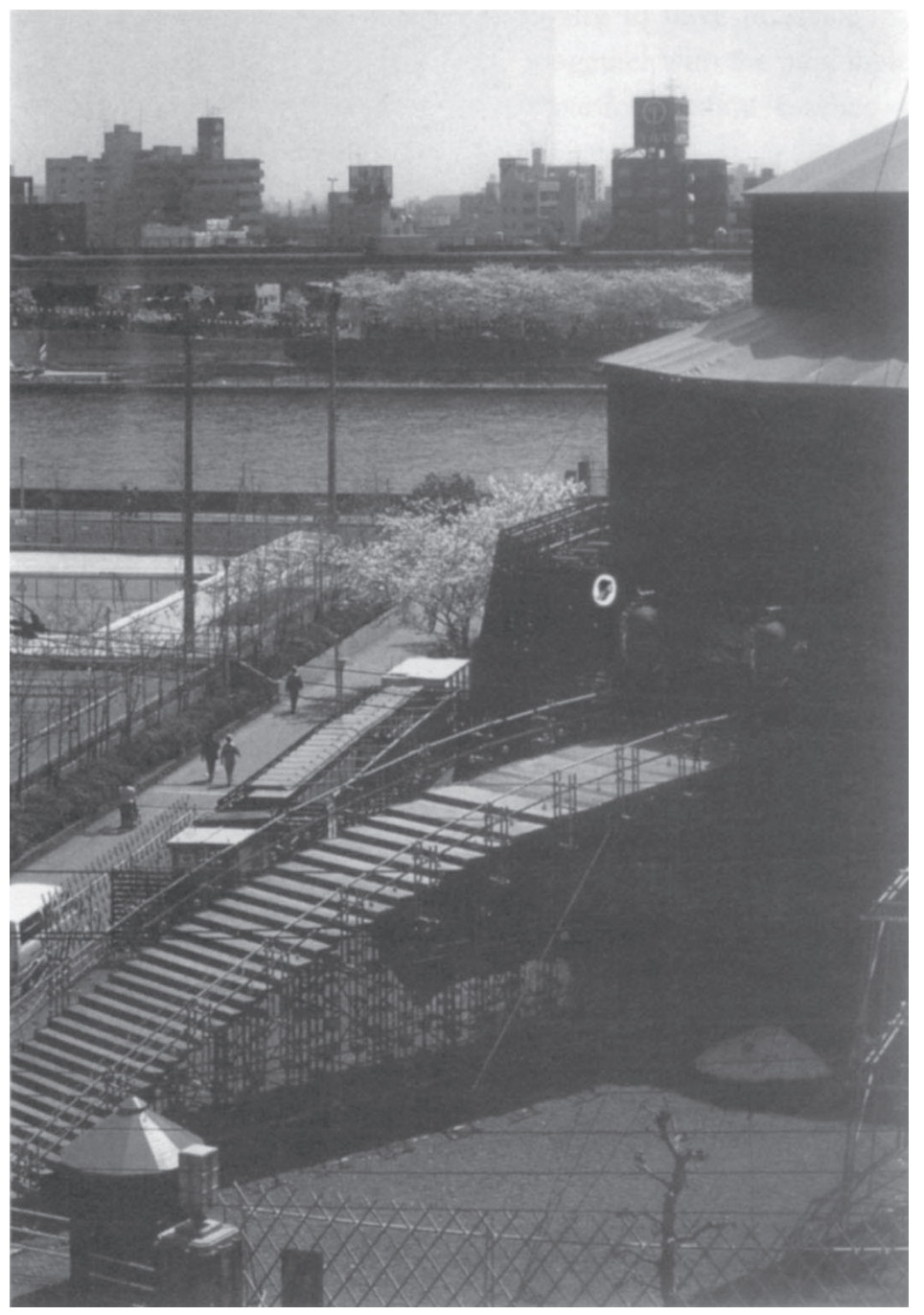

age respect for the past, commitment to the future, as well as trust in the universal applicability and effectiveness of one's particular religious activity, which in turn is limited by its place and time.

With Kara-za (Figure 3), a theater intended to be temporal and portable, it is not at all difficult to discern Vitruvius's ideal theater with four equilateral triangles. Ando, however, is not so much interested in deriving a meaning from an architectural type whose meaning is endowed by tradition, as to search for "the original form of space." ${ }^{24}$ For Ando, it is not that the East held the twelveyear cycle in its calendar, or the West counts twelve months in a year, that assigns meaning to the dodecagon. Instead, Ando believes that there is something inherent in the dodecagon that has allowed twelve to be a perfect number in different cultures, just as it allows the architect, either Vitruvius or Ando, to represent the notion of the world or the cosmos in this form:
Figure 3. Tadao Ando, Kara-za, Tokyo, Japan. (C) Shinkenchiku-sha
24. Ando, T., "A wedge in circumstances," Shinkenchiku (February 1977), p. 219. 
Figure 4. Tadao Ando, Forest of Tombs Museum, Kumamoto, Japan.

(c) Shinkenchiku-sha
25. Ando, T., "Kara-za, a Movable Theater:An Interview with Tadao Ando," Perspecta, Vol. 26 (1990), pp. I7I-184.

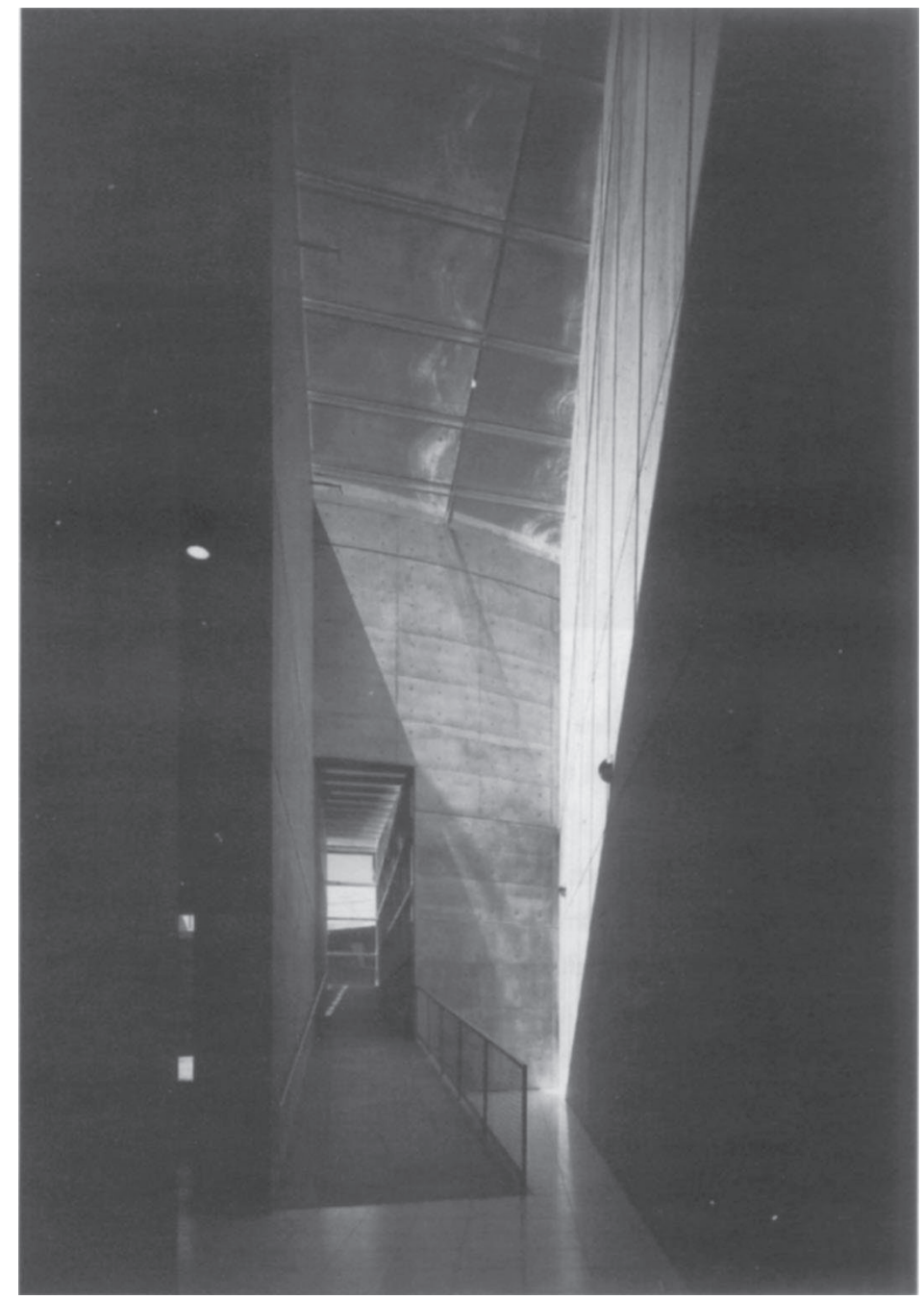

I think a dodecagon represents the world. The number twelve is symbolic of the cosmos. In Japan, there are twelve animals corresponding to the twelve-year cycle of the calendar. In the West there are twelve months to a year and so forth. ${ }^{25}$

For making a world, Ando uses a bridge as both a connector and separator between the world outside the theater and a second within the theater. In reference to his Japanese Pavilion for Expo. '92, Ando stated, "The bridge in this pavilion takes visitors to a fictional world, a world of dreams. Then again, it is a bridge spanning East and West." ${ }^{21}$ Making a world, supported by the intrinsic properties of architectural design, works especially well in the case of a theater. A theater, after all, is a place in which a production, with its specificity of time and place, represents what is universal in time and place. The world of production is nothing 


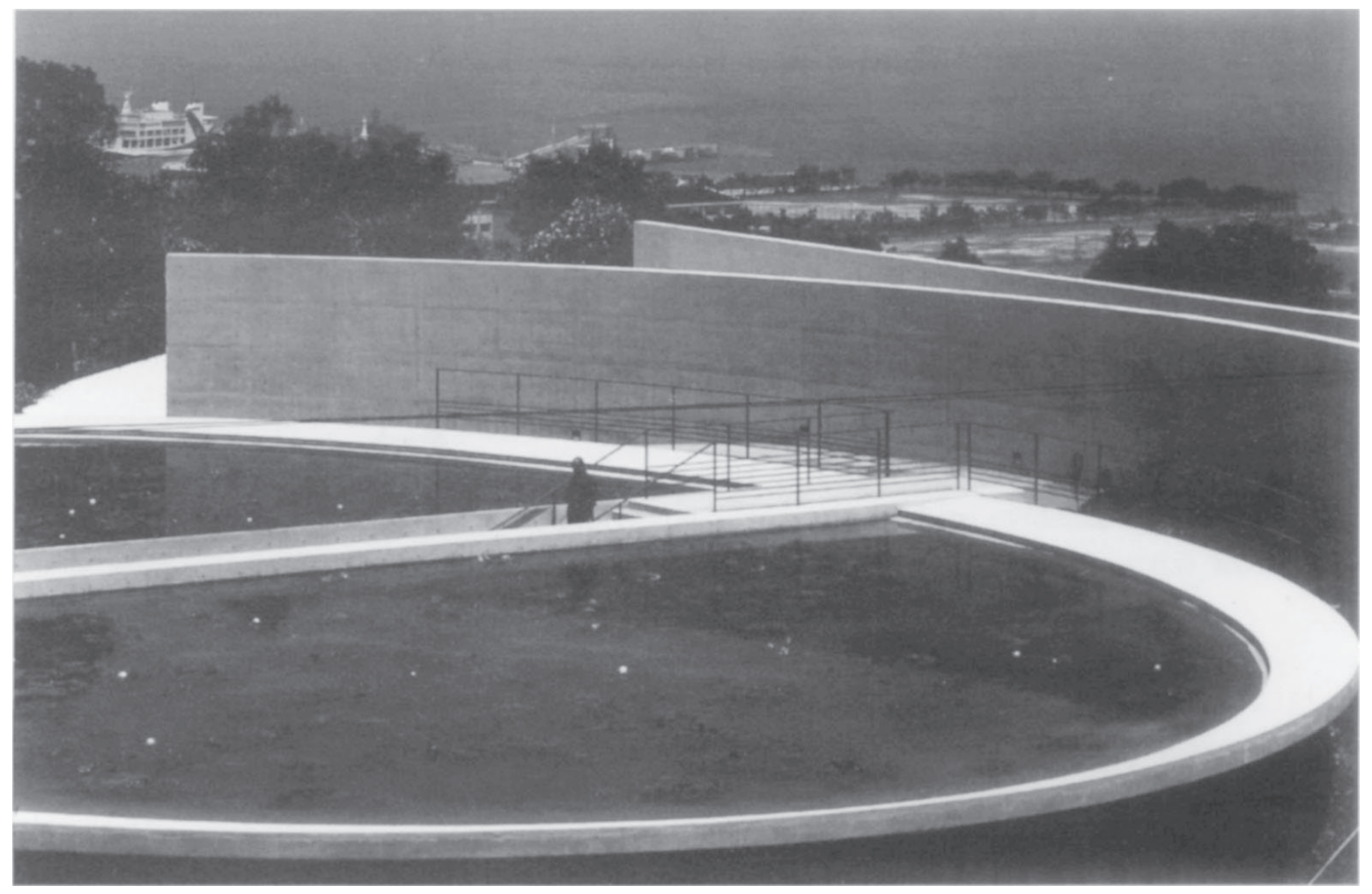

Figure 5. Tadao Ando, Water Temple, Hyogok, Japan. ( Shinkenchiku-sha

but an illusion that disappears as soon as the play is over, and yet, the truths about humanity told in this fragile production stay alive beyond the production as long as they are remembered. Supporting this notion of theater as a temporary creation of an illusory world, which in turn is applicable beyond the theater production, is the use of scaffolding as the building's structure made visible at eye level as well as at the central pinnacle of the space. Here, once again, the material is presented to the viewer in its purest possible condition. The result is a traveling theater that is rich in architectural properties that have high potential for generating interpretations, without relying on any specific cultural training or knowledge on the part of the viewer.

In the Forest of Tombs Museum (Figure 4), although the geometric composition may come from the form of ancient tombs, the meaning does not depend on this reference. Instead, geometry provides "the foundation or framework that enables a work of architecture to have presence." ${ }^{21}$ The pure geometry of circle, grid, and diagonal, together with the pure materials of reinforced concrete, is to embody in the particular some essence of the eternal and the infinite. 
In this museum, the most significant space is that created between the orthogonal of the grid and the diagonal. Here, topped by a clear skylight with a minimum metal frame, the space is directly connected to the sky, suggesting the universal.

And finally, in the Water Temple (Figure 5), historically based typology for Buddhist temples has disappeared altogether. Instead, the water is the element of nature, controlled by the architect's design. When one descends the stairs, to a level below the water's surface, its physical and intrinsic properties bring significance and signification to this piece of architecture.

Trusting architecture's intrinsic properties, when they are pure to the point of abstraction and rudiment, is not an easy path. To gain from them both signification and significance requires commitment and effort from the architect and the general public. Neither will be able to take refuge in the naive relativism of, "anything can mean anything," or "that is just your opinion." However, this may be the path for architecture to regain its significance for the next millennium and a way for every person on the earth to take humanistic challenge and satisfaction in return for appreciating a fellow man's artifice.

\section{Acknowledgments}

The author is grateful to the University of Nebraska-Lincoln Research Council and College of Architecture for their support for this work. 